\title{
Addressing Externalities: An Externality Factor Tax-Subsidy Proposal
}

$$
\text { Jay Cooper Beeks }{ }^{1,2 *} \text {, Thomas Lambert }{ }^{3}
$$

${ }^{1}$ Marylhurst University, Marylhurst, OR, USA

2 Arizona State University, Tempe, AZ, USA

${ }^{3}$ College of Business, University of Lonisville, Louisville, KY, USA

*Corresponding Author: jaycbeeks@gmail.com

Citation: Beeks, J. C. and Lambert, T. (2018). Addressing Externalities: An Externality Factor Tax-Subsidy Proposal. European Journal of Sustainable Development Research, 2(2), 19. https://doi.org/10.20897/ejosdr/81573

Published: March 8, 2018

\begin{abstract}
Nature is losing the war against capitalism and needs us to come to her defense in a way that may seem counter-intuitive. We, humans, have our ways of doing things and natural processes follow their own courses, often distinctly foreign to our inclinations. Our modern-day business practices are designed for the short term, are self-centered, tending toward precision and inevitably leading to environmental destruction. Natural processes, on the other hand, are intended for the long term, are generous, are highly imprecise and almost always lead to flourishing ecological systems. While humankind produces primarily negative externalities, nature produces almost exclusively positive externalities or no externalities at all. This paper discusses a way that both negative and positive anthropogenic externalities can be used to encourage 'good consumption' and to discourage 'bad consumption' for the benefit of natural ecological systems, human societies, family units, and our future generations.
\end{abstract}

Keywords: systems thinking, externalities, externality factors, subsidies, green taxes

\section{INTRODUCTION}

The predominant economic system of the 21 st century, capitalism, is remarkably resilient, in that it encourages innovative behavior, has contributed to countless improvements in the human condition, and compares favorably to the past and less successful economic systems of mercantilism and feudalism. Capitalism is now our mainstream system of economics, which is referred to here as the post-WWII synthesis of neoclassical microeconomics and Keynesian macroeconomics. Like those displaced systems of the past, however, capitalism is at odds with natural ecological systems because the drive to make a profit often comes at the expense of natural systems, in turn negatively impacting human systems as well. This profit motive-profit for the sake of profit, without sufficient regard to environmental impact - is what makes our system of capitalism the enemy of nature (Eisenstein, 2007, 2011; Kovel, 2007; Lilley et al., 2012). Kovel (2007), in fact, declares that we must end capitalism at once if there is any hope of saving the world, saving natural systems, and saving ourselves from our own over-consumptive tendencies exacerbated by an economic system that encourages over-consumption.

To be fair, other systems such as socialism have also proven to contribute to environmental destruction. However, capitalism is the focus of this paper as the dominant economic system of our time. Profits made from environmentally destructive practices, borne by the rest of society in the form of externality costs, can be described as a war on nature by capitalistic forces. When natural resources are exploited through the practice of resource extraction or when our natural environments are used as dumping grounds, this causes destruction and disruption 
to ecosystems, creating negative externalities. These practices then lead to further harm to both natural and human systems.

\section{EXTERNALITIES ARE EVERYWHERE}

Perhaps the best known and the most alarming of these externality consequences today is the phenomenon of Global Climate Change (GCC) caused by our production of externalities in the form of greenhouse gases (GHGs) (Houghton, 1996; Solomon, 2007). Our largest GHG contribution is anthropogenic carbon dioxide (CO2) followed by methane (CH4), nitrous oxide (N2O), ozone (O3) and chlorofluorocarbons (CFCs) (Flannery, 2006; McKibben, 2006, 2011; Protocol, 1997; Solomon, 2007). GCC is starting to capture the attention of the average citizen. However, it has been known for several decades that GCC is caused by producing GHGs from the burning of fossil fuels and that $\mathrm{CO} 2$ production, for example, is exacerbated by the destruction of rainforests around the world, nature's carbon sinks (Houghton, 1996; Protocol, 1997). In addition, humans produce copious quantities of $\mathrm{CH} 4, \mathrm{~N} 2 \mathrm{O}, \mathrm{O} 3$ and CFCs, all contributing to global climate change as well (Flannery, 2006; McKibben, 2006, 2011; Protocol, 1997; Solomon, 2007).

These GHGs come from a wide range of anthropogenic processes such as farming, burning fossil fuels, burning forests, extracting fossil fuels and designing products that use chemicals such as CFCs. Importantly, human activities like these are directly linked to capitalism because of the profit potential in so many of these cases. And in each instance, the externality is a byproduct of our consumption patterns, not sufficiently paid for by those benefiting the most from the sale of the products. Crucially, humans today face an urgent problem with the extreme and imminent consequences of GCC that are directly linked to the unremitting exploitation of natural resources combined with the associated pollution of GHGs all attributable to capitalist, market based economies (Klein, 2014; Kovel, 2007; Lilley et al., 2012; McKibben, 2006, 2011; Wells, 2013).

It has been said, in fact, that consumerism is eating our future, that consumption alone explains the advent of the new Anthropocene epoch (Coghlan, 2009). Carbon consumption has our attention in particular, however, the resulting problems associated with GCC lead to loss of habitat as well as water and land resource degradation. Overconsumption in general, it is argued here, is also leading to the Sixth Great Extinction event in our lifetime, a problem that can best be addressed by reduced consumption worldwide (Hawken, 2010; Klugler, 2014; Krugman, 2010). As Hawken (2010) has tried to warn us, we mistake our ability to consume with the Earth's ability to provide and, in fact, we humans reached the Earth's carrying capacity based on consumption at that time in 1983 (Trainer, 2011). Many economists today are acutely aware of the Earth's carrying capacity, and they contend that our current trends of hyper-consumerism, consumption, and tendencies toward materialism practices must be completely reversed (Daly, 2009; Trainer, 2011; Victor, 2008).

Negative externalities such as air and water pollution and the ensuing impacts on all of us are contingent upon the polluting industry or process, suggesting that the elimination of these processes is the most desirable option, enforced by regulatory action and including internalizing these externalities into the costs of products producing this pollution. Thus, in the case of vehicular exhaust emissions, eliminating the use of gasoline and diesel would arguably be the most effective solution to eliminating the pollution from the use of these fuels. Increasing the cost of these fuels by taxing these externalities holds the promise of reducing the emissions from these vehicles due to the anticipated lower use of these vehicles. In addition, the gradual and steady elimination of products such as fossil fuels with high negative externalities is encouraged due to the anticipated lower consumption of high externality products, thus gradually reducing the profit incentives for the producers.

Fossil fuel industries are extraordinarily profitable and yet these industries are not currently held financially accountable for the end use of their products, or in many cases, the release of these products into the environment during production and distribution. The pollution from the fossil fuel industries include chemical byproducts released during extraction, chemical pollution at the point of extraction, pollution resulting from spillage during transportation, and off-gassing during refining activities. Similarly, farming industries such as palm oil or sugar cane plantations gain enormous profits from the sale of their products, and these farms are too often established where tropical rainforests once stood (Assessment, 2005a, b, c). In the case of these farming activities, the release of GHGs occurs when the rainforests are clear cut or burned, and added to this, global atmospheric CO2 concentrations increase due to the loss of rainforest trees and their ability to sequester carbon.

These examples are just a few of the better-known human activities leading to the creation of externalities, external costs, and externality consequences. There are numerous other lesser known externalities and countless examples of externalities that are rarely if ever considered. In fact, externalities are everywhere and humans are masters at creating an ever-growing list of primarily negative externalities (Spash, 2010). Although it is known that externalities represent social and environmental costs, the identity of many of them still eludes us, and for some of those identified, it is unclear whether they are positive or negative. Therefore, assigning an exact cost is neither practical nor possible (Martinez-Alier, 1988, 1995). Further, assigning costs to just a few readily identifiable 
externalities does not address the systemic problem (Kapp, 1978; Spash, 2010). CO2, as an example, is an externality produced by humans, however, where this gas is produced; many others are also produced such as CO, NOx, SOX, ozone and so on, and all of these pollutants deserve the same attention being provided to CO2. The dilemma of attaching a cost to externalities has to do with the pervasive nature of externalities, the seemingly increasing number of unknown externalities and the very difficult task of quantifying any externality sufficiently to transpose that volume into a currency exchange amount. This difficulty gets even more challenging when we start to examine worldwide externality production, trying to tie this production back to the source and then attempting to add in the many ecological and human systems costs that can be attributed to the original production.

Before listing other examples of externalities, it is important to discuss just what an externality is. In economics, an externality is 'the side effect or consequence of an industrial or commercial activity that affects other parties without this being reflected in the cost of the goods or services involved' (Oxford Dictionaries, 2015). In the case of negative externalities, one entity avoids the cost of externalities from products they produce, and hence they place the burden of that externality on society in the form of external costs. An obvious example of these external costs are the manufacturing processes that create air or water pollution that result in the burden of cleanup costs on society as well as the health impact costs on those directly or indirectly affected by this pollution (Vineis and Husgafvel-Pursiainen, 2005). A positive externality example may be a neighbor who plants several beautiful trees on their property, which aids the surrounding community by increasing the value of others homes. An externality such as this also benefits the neighborhood due to the aesthetic value of the trees as well. Further, a production externality occurs due to production activities and a consumption externality occurs due to consumption activities.

There are, however, countless other anthropogenic externalities because it seems there is very little that humans do that does not lead to externalities of some form or another. As it turns out, externalities are created at an alarming rate, some economic and some not, and the vast majority of them have negative impacts on both our environment and on us. Complicating the problem further, there are very few methods for identifying, reducing, capturing or compensating for these externalities. Externalities are after all, ubiquitous - humans are like externality generating machines and to a large degree, most don't even know they exist or that we produced them. But exist they do, and they come in many, many forms.

An examination of ecosystem services helps to shed light on how natural systems produce positive externalities on a continual basis. Essentially, ecosystem services are the benefits or positive externalities humans gain from ecosystems. Natural ecosystems produce food and water, help to control climate and disease, ensure nutrient cycles such as crop pollination and they provide humans with recreational as well as spiritual benefits. It is hard to pinpoint any one benefit of a natural system as being the most advantageous for humans; however, the conversion of carbon dioxide to oxygen is arguably the most important to our species. Another highly beneficial positive externality from natural systems is the production of clean water. Humans also benefit immeasurably from the production of food from ecosystems services, such as all of the fish from the oceans used for human consumption. Arguably though, one of the lesser appreciated positive externalities produced by natural systems is the ongoing ecosystem service of cleaning up most forms of pollution, both natural and human-made.

One of the first to introduce the concept of externalities and to also propose a tax on them was Arthur Pigou, a well-recognized early 20th-century British economist from Cambridge University. Pigou hoped to not only reduce the human propensity for generating externalities but to create a level playing field for all businesses by ensuring that some businesses pay a more compensatory price for passing their external costs on to others. Proposals today for a carbon tax are based on the Pigouvian Tax first proposed in 1920 in Pigou's work The Economics of Welfare (Pigou, 2013). Pigou also proposed a Pigouvian subsidy for positive externalities generated, such as the indirect and unaccounted for health or education benefits that occur in some transactions, such as schooling or the external benefits of a flu shot. Providing public education benefits all of society, and promoting and providing flu shots at reduced costs even benefits those who do not receive a flu shot thanks to the reduced probability that they will get the flu due to so many receiving the flu shot (Mankiw, 2015).

A weakness of the Pigovian tax or subsidy idea is the inability of the government or any other entity to "accurately" determine the cost to society imposed by negative externalities. Pigou argued for fair competition; therefore, externalities need to be accurately accounted for and taxed and subsidized accordingly. It is reasoned here, however, that this desire for accuracy creates a hindrance for those wishing to impose accurate costs on externalities and in effect, creates an unresolvable dilemma. Furthermore, this tendency toward accuracy and precision is a human tendency, not seen in natural systems. In the end, in fact, externalities cannot be accurately accounted for in a very precise manner due to the complexities of policy analysis and benefit-cost analysis (Gramlich, 1990; Mankiw, 2015; Kraft and Furlong, 2015).

In contrast to Pigou's desire for accurately accounting for the true and actual cost of externalities, Paul Hawken (2010) in his book The Ecology of Commerce: A Declaration of Sustainability offers us some latitude in this area. He proposes, "trying to measure negative costs is preferable to ignoring them altogether, that it is better to be approximately right than completely wrong" (p. 82). Hawken (2010) adds, "perhaps we will never be able to 
accurately predict the external costs of any one process, but we can at least assign a cost to inaction” (p. 98). He insists, though that "any time there is inefficiency in the form of pollution or waste - it is uneconomic and therefore more costly" (p. 152). In general agreement, Daly (2009) has proposed taxing polluting activities, resource extraction and resource depletion, all without connecting the precise cost of these activities to the tax.

Ronald Coase, an economist from the University of Chicago and recipient of the Nobel Prize in Economics in 1991, is another important contributor on the subject of externalities. Coase (1960) proposed that societal and environmental costs not born by a company responsible for generating these externalities are examples of a market failure. Coase's argument, in contrast to Pigou, was that neither the polluter nor the sufferer of the pollution is solely responsible for the cost of the pollution, and therefore the costs should be shared (Coase, 1960). Coase took the position that externalities are primarily an equity issue, and that externality consequences should be distributed fairly between the affected parties depending on who bears the brunt of the responsibility.

Coase argued for equitable transactions between those responsible and those affected by external costs, with minimal to no government involvement. The problem with Coase's position, however, was that equitable arrangements like these make more sense for simple party-to-party transactions and less sense with societal, and even global issues such as CO2 pollution. One person can ask a neighbor to turn their music volume down and hope that they listen and comply. That same approach, conversely, becomes less practical with regard to anthropogenic climate change. Ironically, though, it is the Coase Theorem that has been adopted as the basis for a global GHG trading mechanism as proposed by the Kyoto Protocol in 1997 (Zerio and Conejero, 2009). Thus far, this practice has not proven successful in GHG emissions reductions, and the argument is made here that other methods are more promising than trading mechanisms (Hawken, 2010). These include direct regulation, and taxes and subsidies as first proposed by Arthur Pigou as a way of directly inhibiting externality production. These taxes are commonly referred to as green taxes, sin taxes or green fees and the subsidies are commonly called green subsidies.

Perhaps the best known and the most vocal advocate for green taxes and subsidies today is Paul Hawken (2010). Hawken's concern with pollution permits is that they do just that - permit pollution (2010). In contrast, in Sweden, for example, fossil fuel taxes are imposed on the sale of fuels as an eco-tax. Importantly, however, these eco-taxes (or green taxes) are used to reduce pollution but are not indicative of the actual externality costs associated with fossil fuel use (IPCC, 2007). The eco-tax in Sweden is 8.285 kronor per liter (IPCC, 2007). Sweden uses both a carbon tax and an energy tax (both green taxes) to provide tax revenue and to thwart fossil fuel consumptions in line with recommendations from carbon tax supporters in the US (Carbon Tax Center, 2016).

Hunt (1980) also determined that externalities are not only absolutely pervasive but called them the "Achilles' heel" of our present system of capitalism. Klein (2014) warns us that GCC changes everything with regard to the misconception that free market forces and unfettered capitalism may be allowed to both create and counter the damaging effects of uncontrolled consumption. She and others insist that we must now counter the forces of capitalism, overturning capitalist, market driven political systems, as necessary, in order to adequately address the looming and yet increasingly urgent problem of GCC (Klein, 2014; Eisenstein, 2007, 2011; Kovel, 2007; Lilley et al., 2012). Eisenstein (2011) added that the practice of imposing externalities on to future generations, our natural systems, and present society is inherently destructive. Turner et al. (1994) demonstrated that negative externalities are the actual costs of economic growth and called for them to be included in the price of goods and services. Many economists today, in fact, see the problem with externalities in the form of detrimental costs passed on to society, although there are few viable solutions along these lines, ensuring some form of accounting for externality costs for goods and services.

They are a well-recognized problem, and it is also agreed widely that as long as it is profitable for one entity to produce externalities, they will produce them and their impacts will be passed on to so society, absent government actions to the contrary. Laws meant to prevent pollution, for example, do have the effect of limiting polluting activities and do affect the profit for certain products. There are though, simply not enough of these laws to make the differences needed, and laws alone have not proven sufficient to safeguard against these impacts. The argument against accounting for externalities, in fact, often points to the difficulty of accurately accounting for them and the challenge of determining the economic cost imposed upon natural systems. This argument, nevertheless, creates the false idea that they can be accurately accounted for, when in fact this is neither necessary nor possible. Rather, an imprecise externality factor system is proposed in this paper, an externality factor (EF) accounting concept that attempts to influence consumption and production without the need for precision. This EF system is a taxation and subsidy system based on externality factor values described later in this paper.

Others agree that the value of environmental assets or environmental pollution can be estimated and there is no real need to be exact (Derber, 2010; Pearce et al., 1989). Economists, for the most part, concur that an accurate accounting of many of our endeavors is not realistic. As an example, a benefit to cost analysis relies on several assumptions that lead to the final outcome, and these assumptions are in themselves inexact. A benefit to cost analysis as performed by environmental economists can provide ridiculously precise numbers, although, they are 
also often based on subjective assumptions. For environmental impact estimates, some economists attempt to equate environmental welfare change with human capital using hedonic pricing which incorporates value characteristics beyond the value, say, of just the resource (Pearce, 2002). Even environmental economists though will admit these estimates are speculative and other economists such as ecological economists will refute them altogether as being highly imprecise (Beeks, 2016).

Therefore, the argument here is that a rough estimation of an externality cost can and should be sufficient, and the inaccuracy of this estimate can be communicated early, so as to not mislead anyone into thinking that accuracy is the goal. Examples of products today with imprecise taxes include gasoline (petroleum fuels), cigarettes (tobacco), beer and hard liquor (alcohol). All of these products have a tax on them, taxes on alcohol and tobacco are often referred to as "sin taxes", and yet these taxes do not accurately account for many of the societal or environmental costs associated with either the use or the production of these products. Granted, sin taxes are not externality taxes or green taxes, yet they influence the purchase of these goods in much the same way that externality taxes can. As an example, in several countries in the European Union, higher gasoline taxes, acting as carbon taxes in effect, influence not only the consumption of gasoline but have widespread influences beyond just the consumer behavior at the gas pump. The higher gasoline and diesel taxes in European countries have led to higher efficiency vehicles based on customer demand, higher usage of mass transit, and these taxes have arguably influenced automakers to alter their manufacturing processes to not only produce higher efficiency vehicles but also to switch production to electric vehicles (EVs) as well (Bloomberg, 2017).

The range of varying gasoline taxes from one country to another across the planet may indicate just how much variability there can be in this kind of taxation if we change its intent and identity to an externality tax. In effect, the difference among gasoline taxes, sin taxes, eco-taxes, carbon and green taxes can be considered to be primarily in the name associated with them, not considering the purpose of the revenue generated from each. Of course, sin taxes usually target goods that are considered harmful to one's health, such as alcohol or tobacco products. There are also luxury taxes (e.g., taxes levied on yachts, gourmet foods, etc.), although a fine line can be drawn between one person's idea of luxury and that of another person's conception of luxury. Gasoline may be considered a luxury to those who can just as easily walk or ride a bike to work, and attempts to control emissions from gasoline consumption through taxation or regulation, especially the banning of the use of lead in gasoline, can be described as an attempt to improve the health and well-being of the members of a society. The proposal here is to use this same variable and inaccurate kind of a taxation model and lump these various forms of taxation into an externality taxation system, while not impacting cost-push inflation substantially and therefore not over-burdening lowerincome consumers.

Taken a step further, any externality estimate that results in a corresponding tax needs to be somewhat inexact, acting as an influence on cost rather than an estimation of the actual harmful effect of a given externality. Thus, the taxation system proposed here is to not be too specific, or attempt to be precise, and thus control our propensity for accuracy. If there is a prevalence of "bounded rationality" in economic behavior, a less than perfect system of rewards and incentives will have to "satisfice" (a term coined by Herbert Simon (1957), or yield satisfactory solutions since optimal ones are often elusive (Simon, 1957). In fact, the assertion here is that our economy and economists need to accept compromise, bounded rationality and adapt to new, ambiguous and imprecise ways of doing things in order to address all-pervasive problems such as these. Importantly, the purpose is to influence consumer and producer behavior across the board in such a way that both are influenced over the long term.

Consequently, if our system of economics is adjusted to account for externalities in a 'rough way', then this course of action needs to be accepted along with the rough outcomes that come with it. As an alternative to focusing on exactness, the focus is instead on the desired end results of less waste, less pollution, higher efficiency, more equity, healthier ecosystems, cleaner air, cleaner water and a more livable climate. It is already a given that the precise accounting of externalities is impossible, so why not simply accept this imprecision and move on with imprecise, yet effective solutions? This acceptance of imprecision, in fact, in varying forms across the globe with each country adapting their needs and constructing the changes warranted to meet the long-term goals of both providing needed revenue and reducing consumption related environmental impact, may be our best path forward.

The clock could be running out of time in order for us to address our environmental problems. Climate change, ecological systems destruction, and species decimation have reached a point of criticality that now calls for real action, a viable response. Simply put, society does not have time for a highly accurate accounting of externality impacts, even if it was possible. Granted, those that profit from the creation of these external costs will not accept this kind of accounting result. It can also be expected that an imperfect approach will be challenged at essentially all levels. However, if one is armed with the knowledge and flexibility that the outcome will not be exact, then the outcomes may not be critiqued to the point of exhaustion. All producers, retailers and service providers will experience the same degree of inaccuracy—and this should level the playing field. 


\section{ACCEPTING COMPLEXITY, SYSTEMS THINKING, AND AMBIGUOUS OUTCOMES}

Benyus (1997) has made the argument that natural systems can show us the best courses of action when it comes to human systems, based on the millions of years of trial and error solutions in the natural world that have led to the natural systems we know now. The case is made here that this wisdom gained over these thousands of millennium can be applied just as much to our system of economics and to our need to account for externalities as with any other human need. Arguably then, in order to emulate natural systems, our economic systems will need to be realigned and otherwise altered to incorporate systems thinking, natural systems archetypal conflicts, the acceptance of complexity and a paradigmatic shift that allows for ambiguous outcomes (Wells, 2013). Peter Senge, an expert on the intricacies of management and author of The Fifth Discipline: The Art \& Practice of the Learning Organization warns that human systems are held hostage to defective structures (Senge, 2006). Our tendency is to think in linear terms, ignore the circles of causality and to be unaware of the recurrent systems archetypes found in Nature. This blind leading the blind way of interacting with the systems around us invariably leads to waste generation, a lack of efficiency and the inevitable failure of systems that are not realigned to address these deficiencies. Some may refer to this lack of awareness and overly simplistic thinking process as disciplinary thinking as opposed to transdisciplinary thinking (Montuori, 2005, 2008; Wells, 2013). Their concern is that each discipline has its own paradigm along with countless customs thereby compelling those within those disciplines to follow well-established patterns while being essentially unaware of the other paradigms that apply to the same problems they are addressing.

The proponents of transdisciplinary approaches to problem-solving also advise a more generous approach when addressing the ills of human systems such as capitalism, becoming more comfortable with complexity, ambiguity, subjectivity, and inexactness (Montuori, 2005; Wells, 2013). From Senge's perspective, though, we not only need a unification of knowledge across all disciplines, but we also need to understand the natural systems archetypes in order to use the lessons learned to correct the flaws in human systems (Senge, 2006). He argues for the need to accept complexity, ambiguity, subjectivity, and inexactness, and he states further that human systems must also follow the circular patterns of natural systems that do not lead to the generation of negative externalities. Natural systems often behave in ways that are counterintuitive to us, that are always non-linear, thereby necessitating systems thinking, which is identified by Senge as the "fifth discipline" (Senge, 2006). Systems thinking requires us to contemplate the whole, understand the holistic processes involved with any system and to be aware of the invisible, often counterintuitive processes that are intertwined in any system, human or natural. This new paradigmatic approach called systems thinking is offered now as the antithesis of the past practices of linear and reductionist thinking, demonstrated by the fractional separation of processes with an inclination for precision.

Markedly, circular economists study biomimicry solutions for many of their solutions to identifiable economic problems, especially regarding waste elimination and the need for durable products (Beeks, 2016). Biomimicry is a new science that advances efforts to be more sustainable and that attempts to imitate natural systems designs for use in human designs, for human systems, and as a methodology to better solve human problems (Benyus, 1997). Circular economists are concerned with the need to internalize externalities with taxes, and they are in agreement with other economists in this area including green and compassionate economists as well (Andersen, 2007; Beeks, 2016). Circular economists, green economists and compassionate economists along with several other alternative economists such as degrowth, no-growth, and steady-state economists are just a few groups that see the need for human systems to emulate natural systems, and just one way we can do this is by creating goods that avoid the waste elimination process either through reducing, reusing or repurposing many items used in consumption and production (Beeks, 2016). Another way we can emulate natural systems is by internalizing our negative/positive externality costs/benefits by taxing/subsidizing them and by at least partially including this cost/benefit in with the price of goods and services. In order to make this progressive step forward, however, we need to be willing to accept ambiguous outcomes and be prepared to alter course as needed based on results. Supporting this position, Wells (2013) discusses the challenges of a sustainable society pointing to the need to accept the complexity of our human systems and challenges us to move to a systems thinking approach to problem-solving, accepting that essentially all human systems can be modeled as if they were ecological systems.

Our desire for exactness and certainty has been called a need for security, "an attempt to flee from the contingency, uncertainty, and the ambivalence of everyday life" (Bernstein, 2005, p. 24). Natural systems, on the other hand, appear to thrive on complexity and are full of uncertainty, even blurring the lines between the past, present, and future (Benyus, 1997; Wells, 2013). Thus the argument here is that natural systems, by their very nature, accept the ambiguity of future outcomes, and their tendencies toward redundancy and diversity allow them to adequately adjust to changes as changes arise. Therefore, if our species is to learn from the many examples of natural systems, there will need to be a general acceptance that complex problems often need complex solutions and that ambiguity can be our ally rather than an irreconcilable problem with which to grapple. This acceptance will also mean arresting our inclination to over-simplify problems because by oversimplify things, problems are 
often made even deeper and more difficult to solve (Senge, 2006; Wells, 2013). This new way of thinking applies as much to GCC as it does to any of the problems humans have generated. As Hawken (2010) points out, we need long-term thinking that results in long-term carbon management with the aid of knowledgeable climatologists, environmental scientists, industry experts, and economists. If we are to contemplate the whole - the planetary impacts from our consumption patterns, then this forces us to consider the long-term consequences of either inaction or of bickering over the exactness of our methods. Another way of saying this is that we need systems thinking that is transdisciplinary to solve essentially all of the complex problems we face in the 21 st century.

\section{THE EXTERNALITY FACTOR CONCEPT}

The idea here is to create a system that makes doing the right thing easy for the consumer. In Hawken's words, "We need to take advantage of our natural goodwill and create a system that makes doing good as easy as falling off of a log" (Hawken, 2010, p. xii), thereby, providing a system that encourages a higher number of beneficial purchases and a lower number of harmful purchases. All of these purchases, it is argued, result in processes that are either harmful to society and the environment or the opposite. Therefore a system, such as an externality factor system is needed to influence consumer-buying and supplier production patterns that will then feedback to the production and extraction practices that are ultimately the cause of the externalities. Further, externality factors (EFs) are proposed as a way of influencing positive and negative consumption and production of goods and services without the pretense of being exact. As stated earlier, there are several challenges to accounting for externalities and only one of them is the challenge of accurately accounting for the cost/benefit of a given externality. Another challenge is simply identifying and quantifying all of our positive and negative externalities. A third, and perhaps the most daunting challenge is that externalities occur before, during and after goods are purchased or services are rendered. As an example, if one buys a gallon of gasoline, the externalities of pollution have already occurred with the drilling, shipping, and refinery processes; are occurring at the gas pump with leaking fumes; and will continue to occur after the vehicle is driven off with that gallon of gasoline emitting various pollutants out of the tailpipe. A fourth difficulty is that by accurately accounting for all externality costs/benefits, the cost of goods and services may become too high. The risk of costs being too high is the detrimental impact that this will have on the economy, bringing in excess cost-push inflation and all of the risks associated with an over-inflated economy. Assessing subsidies at too high of a value could also cause problems in that rewards and resources could be misallocated such that some rewarded activities may not be that beneficial. In these cases, perhaps it would be best to start with a tax/subsidy system that assesses externalities at a modest level and that can be gradually phased in as the economy is given time to adjust.

Ecological economists (Costanza et al., 2014; Costanza et al, 2017) have recently determined that human consumption activities have decreased the value of natural ecological services from 1997 to 2011 due to land use change to around \$4.3-20.2 trillion per year. These researchers also strongly advise that all economies move away from the gross domestic product (GDP) as an accurate measure of economic activity and move to a new economic paradigm that puts ecosystem services valuations at its core. Accurately accounting for the cost of resource depletion, however, and then attempting to incorporate these externality costs into the costs of goods and services is not an advisable tactic because of its imprecision and impracticality, and this can actually inhibit us from moving forward in a positive way. Further, incorporating these kinds of costs into goods and services will likely make them too expensive and would be highly unpopular with consumers as well as the politicians who would be asked to propose these new taxation systems.

This brings us back to the natural processes approaches and of not trying to account for every dollar, thereby avoiding an apparent accounting enigma, accepting inaccuracy as opposed to insisting upon exactness. Natural systems are not sentient per se, and as such are not concerned with this kind of detailed accounting or monetary value of things, and yet most successful natural processes find ways to eliminate negative externalities and promote positive externalities. Considering a systems thinking approach, as advocated by Senge (2006), it is necessary to step back and look at the whole process, accepting that most of our products and services have impacts that are widespread, nonlinear and interconnected to other systems. Similar to natural systems, our solution also needs to be self-sustaining and generous in the process. Thus, the objective here is to find a way to discourage certain detrimental behaviors and encourage other, more positive behaviors without attempting to mandate impossible to achieve precise accounting measures.

Consequently, this EF accounting system proposed here utilizes a broad-brush (blanketing) approach that incorporates past proposals such as the Pigouvian tax and subsidy (Pigou, 2013), the carbon tax (Krugman, 2010), and the energy or gasoline tax (Hsu, 2008). It also follows the recommendations of Hawken (2010) by creating a system that is innovative and that drives customers to make right decisions simply by choosing the least cost option. This EF system is intended to take into account production externalities, consumption externalities, monetary and non-monetary externalities, and whether they are positive or negative. Therefore, all externalities are 
addressed, not just $\mathrm{CO} 2$ or others readily identified and this system is intended to address less tangible externalities as well, such as the possible inhumane treatment of animals along with an unhealthy consumption of animals. Notwithstanding, due to the mass production of many meat items, outbreaks of diseases such as "mad cow" disease, E. coli and salmonella are becoming potentially greater public health threats (Behravesh et al., 2012). An EF system such as this dissuades certain kinds of consumer behavior and discourages over-consumption as well due to the higher cost of certain goods and services. At the same time, it provides subsidies and rewards to those firms and consumers who modify their production and consumption patterns. As an example, a K-Cup single cup disposable brewing pack or single-use coffee cups will have high EFs due to the environmental impact of the resources wasted to produce them, the disposing of these products into landfills, and the inability to recycle them.

There are, in fact, countless examples of single-use items that deplete resources, fill up our landfills, add pollution when improperly disposed of and create pollution in the manufacturing process. Those items that are recyclable or re-usable or those that can be returned for a reimbursement amount (deposit) may not be taxed, and the consumer can be given small amounts of incentives as rewards for re-use or recycling. For those homeowners and vehicle owners who use energy and fuel amounts below an average efficiency, they may be rewarded with payments to help them be able to afford alternative home energy sources and alternative means of transportation, such as re-directing their payments to go to a local mass transit fund. Payments by one group in the form of taxes would subsidize the rewards/incentives paid to those modifying their consumption and production habits.

Likewise, producers who use below a certain amount of resources for their industry may be rewarded through tax revenues paid by producers who exceed a target rate of usage above a certain amount. The entire tax and subsidy system can be set up in such a way as to promote a transition to more environmentally friendly and safer practices and with a gradual phase-in starting with lower taxes and eventually increasing them to approach the actual cost of externalities over time. Thus, a system such as is proposed here, can be gradually implemented with sufficient flexibility to adjust the amount of taxation on any given high externality good, and to do the reciprocal with any low externality good. Further, some particularly "bad" goods that are known to be especially detrimental to society or the environment may be given comparatively higher taxes, in an effort to dissuade consumption of these goods in short order, while still monitoring the overall impact to inflation and certain consumer behaviors.

Unlike a cap and trade system, this EF system does not rely on the trading of externalities, limiting emissions, the sale of emission licenses or the use of professional traders to exchange externalities such as $\mathrm{CO} 2$ or SO2. This EF system differs from a gas tax, a gas-guzzler tax or a BTU tax because it addresses all externalities at once, without special attention to fossil fuels consumption alone. The EF system proposed here, like a carbon tax, however, provides tax revenues to the government rather than revenues to traders or to the industries involved in producing emissions. Another difference is that this EF system relies solely on EF values that affect costs and, therefore, uses market forces to encourage 'good' consumption and production and discourage 'bad' consumption and production based on the retail price of goods and services. Additionally, rewards and incentives are built into the system by granting rewards to those consumers and producers who make a greater and faster effort to move to sustainable consumption and production. Grants and subsidies can be awarded to those consumers and producers who want to employee solar, wind and other alternative forms of energy in their homes and places of business, for example.

Another essential consideration is that this assignment of $\mathrm{EF}$ values needs to be independent of time and place, thus more representative of natural processes. Assigned EF values are independent of time and location because events in the future are anticipated in addition to the known events of the past. As an example, a gallon of gasoline will be priced according to EF values, taking into account extraction, transportation, refining, and potential spills, which all occur before the time of purchase. So, for a retailer in the US, a gallon of gasoline originating from Saudi Arabian oil could have higher EFs than one shipped from Texas, even given the higher energy input per barrel of Texas oil. That is because EFs need to be assigned for all externalities, such as the pollution resulting from overseas shipping and not just the impact on GCC. Consequently, EFs are also assigned with either the known or the projected transportation and packaging externalities accounted for in the price of the good. Hence, the same product shipped a shorter distance and with low environmental impact may have a lower EF value. And local environmentally friendly packaging will have a lower EF than one shipped a long distance with non-biodegradable or non-recyclable plastic packaging. Furthermore, the future use externalities of goods and services are accounted for when the EFs are assigned, such as the end use burning of a gallon of gas or the end use consequences of purchasing refrigeration coolant or pesticides.

Thus, this EF system proposes to address and internalize all of our externalities, inclusively, albeit not with the precision economists are used to striving for. For this purpose then, the need is to identify several externality categories covering our negative and positive externalities. Seven categories were created for the purposes of this 
paper, as a means of providing a general representation of the critical areas that can be impacted by externalities. The categories for these externalities are summarized as follows:
1. Air pollution
2. Water pollution
3. Land pollution
4. Ecological system impact
5. Human or animal wellness impact
6. Societal or cultural impact
7. Global climate change contribution

These general categories are proposed here, though others can be used instead and any of these categories, in turn, can be adjusted with time as the need arises. As stated earlier, the goal is not precision, but rather to have an all-encompassing coverage of all externalities. Another goal is to provide a rough, subjective and adjustable method of assigning a value to negative externalities as well as to positive externalities. This can be accomplished by assigning an EF value to each of the above seven EF categories. These factors can then be multiplied cumulatively times the producer's price for a given good or service. Lower EF goods and services generally have less impact on the environment, create less waste, capitalize on the recycling of materials, utilize renewable resources and have less impact on societies.

The EF accounting system is envisioned to consist of multiplying fractions ranging from values as low as $0.8 \%$ to as high as $1.3 \%$ with divisions between these two extremes of as low as 0.01 , or one hundredth. Multiplying one of the EF categories by a fraction of less than 1.0 results in a lower value assigned to that category that, in turn, will lower the cost of the good or service being assigned this value. In contrast, multiplying one of the EF categories by a value higher than 1.0 results in a higher value assigned to that category, and this will raise the cost of the good or service. Therefore, a number higher than 1.0 represents an overall negative externality evaluation and one below 1.0 represents an overall positive externality evaluation. In addition, a low score in another category can cancel out a high score in another category and vice versa. The final impact on the retail good or service will be determined by the cumulative effect of compounding all of the EF categories and applying them to the goods or services. The process is demonstrated in Table 1.

Table 1. Example of Comparing Two Options

\begin{tabular}{lcc}
\hline Externality Factor Category/Producer Cost & Option A & Option B \\
\hline Producer Originating Cost - Includes Packaging and Transportation to & \$Production Cost A\% (1) & \$ Production Cost B \% (1) \\
Retailer (A) & 0.9 & 1.0 \\
\hline Air Pollution (B) & 0.8 & 0.95 \\
\hline Water Pollution (C) & 1.05 & 1.05 \\
\hline Land Pollution (D) & 0.94 & 1.07 \\
\hline Ecological System Impact (E) & 1.25 & 1.03 \\
\hline Human or Animal Wellness Impact (F) & 0.95 & 1.02 \\
\hline Societal or Cultural Impact (G) & 1 & 1.05 \\
\hline Global Climate Change Impact (H) & $\$ \mathrm{~B} * 1.18$ \\
\hline Multiplying production cost by cumulative externality factors & $\$ \mathrm{~A} * 0.84$ & $(+) 0.18$ \\
\hline A B*C*D*E*F*G*H= & $(-) \$ 0.16$ & \\
\hline
\end{tabular}

For a retailer selling Option A, their average selling price for this good would drop roughly $16 \%$ whereas, for those selling Option B, their prices would go up approximately 18\%. Such a drop in prices from one option to another would provide an incentive to participate in the EF program because the retailer can be rewarded this incentive in the form of a subsidy. Also, as is apparent, the higher EFs are disincentives to the consumer and the lower EFs are incentives to the consumer. The expected end result is that the consumer demand for lower EF products will cause a shift in the production of 'good products' that will mean more - lower EF products over time. Lower EF costs act as subsidies or incentives for the retailer and higher EF costs act as taxes for the retailer.

Since most externalities are in fact, negative as opposed to positive, a typical retailer will have a net tax penalty weighed against all of their goods and services and will be responsible for this tax just as they are now for sales taxes. In addition, the scale can be adjusted downward if there is concern about too many goods or services impacting the consumer price index excessively and adjusted up if there is insufficient revenue to meet the government's needs. Even with these kinds of adjustments, however, good products and services will compare favorably over bad products or services.

The goal in creating these broad externality categories is to keep the backbone of this system fairly simple and to allow room for adjustments as needed. In addition, each country, county, state or city, with each assigning their own EF values for goods and services, affords a great deal of variability and flexibility. There is also no reason why new categories cannot be added, such as a separate category for human wellness impact and a separate category 
for animal wellness impact. Societal and cultural impact categories can also be divided into separate categories. As can be surmised, the more EF categories, the more potential to impact the ultimate retail price, particularly since the categories are cumulatively multiplied by the production costs. Significantly, EFs are assigned to output products and services and could be levied at either the retail level or at each level of the supply chain.

The former way of imposing the tax may place a burden on retailers whereas the latter method would make the EF system similar to a value-added tax (VAT) where taxes are imposed at each point in the product's or service's supply chain. VAT taxes, somewhat of a national sales tax, are popular in most of the industrialized world and have been credited with dampening consumption and encouraging savings in many nations (Lee et al., 2013). Again, to make the EF system more palatable to households and firms, income taxes can be greatly reduced or even eliminated. And output products and services rather than input products and services are taxed in order to reduce the number of calculation assignments needed and to have a more direct influence on the end consumer.

Naturally, there are going to be big concerns about the value of externality factors chosen for any particular good or service, therefore the results are disputable and will be disputed. The important consideration is that EF values need to be chosen - actually - chosen, as opposed to not choosing any value at all in fear of being inaccurate or in order to appease influential forces. Any selection of externality factors, as a matter of fact, will be disputed, as will the reasons given for the assignment of these factors. Moreover, a dispute of the EF assignments for any good or service will result independent of who assigns these values.

The key to the assigning of them, however, is that they are assigned consistently from one situation to the next, with less emphasis placed on the accuracy of the accounting to support the calculation of each EF value. Disputes will still ensue, although, if they are assigned consistently and uniformly by a central government entity or commission there will be less room for disputes based on the grounds of irregularity, preferential treatment or inaccuracy. Economists and accountants with the appropriate expertise will have to be employed initially to calculate and assign EF subsidy/tax values that are fair and efficient. As discussed later in this paper, though, this assignment and calculation of EF values for any good or service needs to done by computational means on a massive scale and with the aid of artificial intelligence in order to make the task both manageable and self-correcting over time. Utilizing computational means also provides anonymity based on the programming functions performed and helps to take the human factor out of the equation. Again though, the subsidy/tax rates do not have to be perfect but should be seen as fair and as a way to appropriately address externalities.

Importantly, even though EFs are assigned to goods and services either at the point of retail sale or at different points in the supply chain, they can be adjusted depending on the practices of a given retailer, distributor, wholesaler, and/or producer. As an example, if a firm depends too heavily on the worldwide shipment of goods, participates in deforestation activities because of the goods they purchase, has inefficient and non-sustainable practices, or is known to rely on unsafe working conditions for the production of goods, among other things, then the EFs can be increased specifically for this firm. Therefore, another firm purchasing the exact same goods that do not use excessive amounts of fossil fuels for shipping, does not purchase goods that lead to deforestation activities and does not purchase from factories with unsafe working conditions may be assigned lower EFs for the very same product.

However, EFs do need to be adjusted over time depending on changing conditions, so if a firm moves away from harmful practices to society and the environment, the EFs for their goods or services can be lowered to be in line with a company with a good track record in these areas.

Additionally, there must be active government control over a system like this to ensure not only uniformity but also accountability. It is a given that retailers, as well as producers, will maneuver, protest, jostle and clamor over assigned EFs and that there will be a kind of death knell outcry over the unfairness of adding these costs to products that are not sustainable. This outcry may then lead to many attempting to circumvent or otherwise cheat the system. Accordingly, accompanying this government oversight, there is the need to have strict penalties for cheating the system, strict enough that only the foolhardy will be willing to take these kinds of chances. Thus, the need for enforcement actions will be lessened thanks to the risk of strict penalties imposed on those who would try to cheat the system. Consequently, the threat of a federal audit will provide sufficient incentive to keep the vast majority of producers, distributors, and retailers compliant.

\section{MAKING IT WORK FOR ALL OF US}

The idea of an externality accounting system is clearly not the solution to all of our socioeconomic or environmental problems and by itself is not going to address all of the concerns with capitalism, our polluting practices and other problems such as wealth disparity. Other solutions employed today need to continue, such as: conservation programs, mandated efficiency improvement programs, the prohibition of certain environmentally destructive practices, stimulus programs for environmentally beneficial technologies, regulations against pollution activities, the continued creation of large-scale national protection areas to protect ecological systems, protecting 
endangered species habitat, preserving clean water sources and wetlands, continuing with restoration projects of critical ecosystems, combating wildlife trafficking, combating illegal fishing activities, and so on. All of these kinds of actions and more as part of any economic system certainly need to continue and to expand in the future. Many of these actions can be funded, however, with the aid of an EF system.

In practicality, the solutions needed for the very real and urgent worldwide problems such as GCC, are best addressed with urgent actions attacking the massive production of GHGs today, such as by reversing the biggest contributors of GHGs outlined in Drawdown: The Most Comprehensive Plan Ever Proposed to Reverse Global Warming by Hawken and Steyer (2017). In contrast, the gradual implementation of an EF taxation system as proposed here is not intended to have the swiftness with which to adequately address or reverse the impending consequences of GCC alone. Rather, this EF taxation system is intended as one of many actions needed to address and eventually reverse the consequences of GCC. Further, many of the problems associated with GCC have been persisting for a long time, and due to prolonged inaction are now reaching a point requiring immediate solutions in order to avert the worst of the predicted consequences.

Our free market approach to meeting human needs has yielded many externalities and contradictions that are difficult to address and reconcile, particularly, in short order. Yet with no anticipated or foreseeable dissolution of capitalism on a worldwide scale, attempts to address GCC have to be done within the current economic framework. This is why this paper has focused on using rewards and incentives as a method of encouraging a capitalistic system to move away from generating so many negative externalities. With regard to GCC, the Paris Climate Accord and recommendations from researchers on the subject including Hawken and Steyer (2017) as well as Klein (2014) may serve as our best and most promising solutions to address the need of reversing the increasing output of GHGs worldwide. The proposed EF accounting and taxation system here is intended for the long-term needs of societies at odds with natural systems and the need for long-term adjustable corrections. In agreement with Hawken (2010), and Wells (2013) there are no easy solutions to a problem as complicated and widespread as GCC. Instead, what is needed is a wide array of solutions that work in concert with one another to counter capitalistic systems tendencies that result in a succession of repetitive calamities such as are already being caused by GCC.

The proposals in this paper are meant to supplement other much-needed actions around the world such as those actions precipitated by the Paris Climate Accord. The findings of the Intergovernmental Panel on Climate Change (IPCC) (IPCC, 2007; Solomon, 2007), and information from the Millennium Ecosystem Assessment Report (Assessment, 2005a, 2005b, 2005c) stand on their own. There is no dispute here concerning the dire warnings from the IPCC that the world must take actions to keep global atmospheric temperatures below 2 degrees Celsius above pre-industrial levels if we are to avoid many of the catastrophic consequences of GCC. The proposals in this paper, although not perfect, are intended to supplement the existing proposed actions needed to address GCC and the recommendation of the Paris Climate Accord.

As stated earlier, directly attacking the causes of GCC as outlined by Hawken and Steyer (2017) may be the most effective course for reducing atmospheric GHGs. By the same token, the majority of the atmospheric $\mathrm{CO}_{2}$ drawdown solutions proposed in this book are directly or indirectly related to human consumption patterns (Hawken and Steyer, 2017). Two notable exceptions are the need to educate girls across the world and the need for family planning across the world. The other top ten global solutions proposed, however, such as changing refrigerants to be non-GHG, building massive wind turbine farms, reducing food waste, eating a plant rich diet, saving our tropical forests, building massive solar farms, switching to silvopasture practices and having considerably more rooftop solar installations can all be tied to consumption patterns as well as the externality categories outlined in this paper. Any of these last eight of the proposed top ten solutions can be benefitted from the EF system proposed here for not only a changed and beneficial consumer behavior, but for funding, made possible by taxation systems such as the EF taxation and subsidy system proposed here. As examples, a higher EF taxation for wood harvested from tropical forests or for beef raised on what were tropical forests will help to discourage consumption of these products and by doing so help to address the need to save our tropical forests.

In addition, the practice of accounting for externalities and the funds obtained from the inclusion of these EFs can accomplish other wonderful things for all of us. These funds can go toward infrastructure projects, public health services, and helping families per Hawken's emphasis on educating girls and establishing family planning; and other programs and can go a long way toward helping economies by putting people back to work. These funds, however, must be used for the greater good, for our society's and for those that come after us, our future generations (Derber, 2010; Schmidheiny, 1992). Hence, these funds need to be used to stimulate our green economy, clean up our environment, protect our natural resources and wean ourselves off of fossil fuels. Just as importantly, the accumulation and the distribution of funds from a program such as this must be adjusted, as needed, so to not unfairly impact lower income consumers and to help lower income consumers with beneficial subsidies and stimulus programs.

The enormity and scale of assigning EF values to essentially all goods and services may only be accomplished by computational means, and this use of computers assigned the task of producing EF values lends itself well to 
both anonymity and objectivity. Given input data such as bar codes, manufacturer, distributor, country of origin and place of purchase, a computer assigned $\mathrm{EF}$ value is possible given that the algorithms are designed properly to make all the assumptions needed in assigning these values. Further, these algorithms may be programed so to assign a predetermined maximum EF value and a predetermined minimum EF value. Thus, in the beginning assignment of EF values it is expected that many more goods and services will have higher EF values as opposed to lower EF values. Therefore, it will be necessary to have the algorithm assign a total value of, say, 1.2 for most goods and services with an actual value computed to be higher than this in order to control inflationary pressures. And with the same reasoning, the algorithm will have a minimum total value of, say, 0.8 for those rare goods and services with particularly favorable, positive externalities.

In the very near future, artificial intelligence $(\mathrm{AI})$ computation aided by multiple feedback inputs and mathematical optimization will greatly aid in the enormity of a process such as assigning EF values to all goods and services, and will likely prove to be essential. One advantage of AI is the ability to self-correct based on feedback input, such as inflationary responses, volume of sales changes, sales of alternative products, demographic consumption patterns and so on (Marwala and Hurwitz, 2017). This feedback and response automation may allow for EF changes that can be incorporated into existing bar codes and may alleviate the need for economists to provide continual oversight on the microeconomic effects of consumption changes over time. A computational process aided by AI, in the beginning, may also simplify the business of assigning EF values and as inflationary pressures permit, those goods and services that continue to be sold with high negative externalities may be assigned comparatively higher EF values, owing to the programming of the algorithms and allowing for time for producers to improve their processes for the benefit of both society and the environment.

Critically, other taxes such as income taxes can be gradually replaced or eliminated by these EF generated green taxes, thereby reducing the financial impact across the board. As Hawken (2010) has suggested, once prices have been established with externalities at least partially accounted for, we then need to shift the tax burden from income to taxing pollution and environmental degradation. A taxation system like this, if designed and maintained properly can replace all other forms of taxation, focused exclusively on consumption. Following Hawken's (2010) advice and paying particular attention to his new book (Hawken and Steyer, 2017), this EF taxation and subsidy system can act as the funding source for all of the up to 100 drawdown proposals needed to reverse GCC impacts. Critically, as stated earlier, these kinds of changes to taxation systems need to be accomplished with lower income families and groups in mind, ensuring that the implementation of a system such as an EF valuation system does not do harm to consumers with lower incomes or for the goods and services they depend upon for their daily needs.

EF funds and taxation practices will help in many other areas as well-they will alter our purchasing patterns and thus help us to help each other. On the other hand, if one thing is known about our system of capitalism, it is that greed will always find a way around any real or perceived barriers. Greed and the love of money are powerful influences and unfortunately, very wealthy individuals will continue to exert control on societies for the purpose of acquiring more wealth. Accordingly, it is a given that many will fight a system such as this and they will likely demand exactness and precision, neither of which being possible or practical. Consequently, there remains the requisite to be ever vigilant of these actions; to resist the inevitable calls for precision at every level. It will also be necessary to put sufficient safeguards and penalties in place to thoroughly discourage those who will continue to acquire wealth at the expense of society and the environment.

In addition, should $\mathrm{EF}$ taxes prove to be insufficient to meet the needs of a given economy, land taxes can either remain or be newly employed. Hence, in concert with lower income taxes or the elimination of income taxes, a national tax on all land values could be levied in order to make up for lost income tax revenues. Such a land (and natural resources) tax was first proposed by Henry George (1881) as a replacement for all other taxes that would be more economically efficient than other forms of taxation. George felt that land and natural resources should be equally owned by all and that landowners earned unjustified income because they actually produced nothing (George, 1881). A land tax along with an EF subsidy/tax system would also be more equitable in that tax burdens would fall more heavily on the wealthy. Programs for low and moderate income people would still be continued, and money to help them adjust to an EF subsidy/tax regime could be set aside in a new program.

\section{POTENTIAL FLAWS WITH EF TAXATION}

What are some of the flaws with a system like this? One is that a less sustainable producer or wholesaler with high EF values may lower their cost for goods produced in order to compete with similar products with lower EFs. This scenario is likely and it will mean the producer will either make less of a profit or that they will eventually lose money with these kinds of transactions. A lower profit or a market loss should dissuade these kinds of dumping practices over the long term. Producers with higher EFs will also face the risk that consumers will favor 
lower EF products even though the prices are comparable. For this to occur, goods will need to be labeled with their final and categorical EF values.

Another potential flaw with this EF system is that some retailers and producers will attempt to rig the system by discounting EFs or even neglecting them altogether. In cases such as these, enforcement actions as mentioned earlier will be needed. Again, the potential of an audit of fraudulent EF value accounting practices needs to act as a sufficient threat in order to limit the number of audits and to keep the enforcement costs down. Businesses that do attempt to rig the system will soon find their businesses in ruins once a full accounting of their practices is discovered and stiff penalties are assigned to them.

The real complication with a system like this is in the assigning of EFs and the seemingly insurmountable task of getting cooperation from industry and the public. No doubt, this is not going to be easy and it will be a bitter struggle from start to finish, however, it can be made easier through grants and subsidies. Those producing more sustainable products, on the other hand, will not be clamoring so loudly and many of them could be the first to jump on the bandwagon. The difficulty though is in coming up with EF values that are agreeable enough to move forward with those producers of goods and services that are not as sustainable. The political will to make the rewards and incentives work is of crucial importance. Perhaps a better nation or set of nations in which to start the EF concept would be in Scandinavia or Europe rather than in the United States because those nations have tended to pursue more progressive political solutions to many problems.

Conceivably this concept could be included in some type of global agreement, like the UNFCCC, since supply chains are global, and the impacts of consumption are often half a world away. Getting agreement and buy-in from different nations would be a challenge, but momentum could be built upon those forces that helped to bring about the Paris Climate Agreement. International grants could also be developed to help developing countries to meet EF goals. This paper does not attempt to address these difficulties in detail, other than to say that strict and usable guidelines need to be established at different government levels, and there needs to be strict enforcement of those guidelines with penalties sufficient enough to discourage fraudulent practices.

The lack of political will in countries such as the United States may present the greatest challenge of all, however, potentially preventing a system such as this from ever getting off the ground. Further, there may be no way around poor leadership in some developed countries, in general, who are adverse to government influencing market forces or any kind of a pollution taxation system. However, there is always hope that the political will in some of these countries such as the United States will change, based on the everyday newly gained information supporting the need for these kinds of measures. After all, it was not that long ago that under the administration of President Barack Obama, the United States did sign onto the Paris Climate Agreement. And it was only after the election of the populist President Donald Trump that the United States took steps to back out of this agreement.

The problems of climate change, though, are not going away and the understanding of the impacts is gaining not only in the scientific arena, but in the public and political arenas as well (Hawken and Steyer, 2017; Wells, 2013). Thus, it stands to reason, that with sufficient public will and with a kind of sea change of public representation, that even countries as seemingly intransigent as the United States will eventually be open to these kinds of recommendations. Arguably, capitalist, market-based economies such as exists in the United States will be the last economies to adopt market influencing systems such as proposed here, and which have a direct impact on the international trade of goods and services. Therefore, it is also likely that pressure from other countries through the United Nations, and pressure exerted directly from progressive trade partners will be needed to ultimately persuade such changes in trade policies with countries such as the United States. Trade policies, as created and enforced by the World Trade Organization (WTO), may be the best encouragement for a progressive externality taxation system such as has been proposed here.

In addition, because essentially all forms of air pollution and most forms of water pollution have direct global consequences, involvement of a worldwide organization such as the WTO is essential for a system such as the EF system described here. It is going to be critical that the assignment of EF values is consistent globally, for any goods or services that are traded between countries. And for the health of the planet as a whole, even products produced and sold locally will need to have EF values that are consistent with EF values used in other parts of the world. Then, an organization such as the WTO, or another organization designed and created for this purpose by the United Nations, will prove to be essential in order to establish an EF system such as this, that is fair and equitable for all nations. The United Nations may also enlist the aid of an organization such as the International Monetary Fund (IMF). The IMF is supported by nations around the world thus allowing the IMF to in turn sustain the WTO with the financial needs as deemed necessary to meet the objectives described in this paper. Just one of those objectives may be the complete reversal of GHG inputs that are leading to global GCC consequences. Many other objectives may also be on the agenda as well, however, such as the elimination of plastic gyres in the oceans, the protection of coral systems, or the replenishment of ocean fisheries in order to meet the needs of future generations. 
Another concern is that production costs for goods will be higher if the products are more sustainable and that higher costs means less profit, potentially jeopardizing certain business enterprises. This will be true for some products and not true for others. Some products can be produced more sustainably at less cost than nonsustainable products. As an example, Nike has responded favorably to concerns that their products were not being produced sustainably following recommendations of their Nike Environmental Action Team (NEAT) in 1993. Nike began making significant changes in the early 1990s with products such as playground surfaces, sporting field surfaces and apparel lines that are made entirely from discarded shoes and recycled polyester (Hauser and Blume, 2011). Other steps have included the elimination of petrochemical based solvents for shoe manufacturing and the gradual elimination of other hazardous chemicals that have actually resulted in significant manufacturing savings as opposed to higher costs (Hauser and Blume, 2011). For many businesses, including Walmart, in fact, the conversion to environmentally friendly and therefore more sustainable operations has been rewarding to the employees, profitable from the production and retail side and advantageous on the marketing side (Rae and Sands, 2013; Nandagopal and Sankar, 2009).

Not all businesses, however, will see these kinds of benefits from more sustainable operations, and will find that sustainably produced products do cost more to produce, affecting their profits and perhaps countering their ability to grow with higher demand. As an example, a farmer producing organic and range fed chickens may find that production costs are higher than for a competitor producing non-organic Concentrated Animal Feeding Operation (CAFO) chickens. Therefore, producers of the organic range fed chickens may, in fact, suffer from lower profits and growth as compared to a CAFO competitor. The opposite may also be true, however, and profits may be higher with more sustainable operations. Many companies have already achieved financial success with organic foods and other environmentally friendly operations due in large part to consumer support for these kinds of businesses (Savitz and Weber, 2014). Therefore companies that have already benefited from environmentally friendly operations will benefit further from an EF taxation system and those that are not environmentally friendly now will have a further incentive to improve their operations in order to keep up with the competition.

Other businesses that refuse to improve their impacts on society and the environment may also fall by the wayside as demand for environmentally friendly products increases. In addition, the higher EF tax attributed to the less sustainable products may negatively impact the consumers of those products and may negatively affect low-income consumers disproportionately. Some of these consumers, however, will find sustainably produced products that are cost competitive while others will not realize these same advantages, suffering financially. Hence, it will be necessary to cap out the highest EF tax initially for most necessary goods in order to protect low-income consumers from the higher costs of essential goods.

As the EF system works and hopefully shows signs of successful implementation and impact, land and property values should rise thanks to the positive externality of cleaner and healthier environments in most parts of a country. A national tax assessed on only the increases in property values after adjusting them for ordinary housing costs inflation would be a way of matching continued program costs with benefits. Such a tax could possibly be added to local property taxes, and the receipts could be forwarded to the federal government. It should not, however, tax away all of the increase in an owner's property value since to do so could weaken household and industry commitment to an EF system. As with local property taxes, allowances could be made for those on fixed incomes, and if income taxes are either rolled back or eliminated, then property tax increases should not be as onerous as would be the case otherwise.

In addition, "bad" goods such as fossil fuel products will see increasingly higher EF values over time, not only because of GCC impact or because of the limited supply of the raw materials, but because of the increasing amount of damage caused by the extraction of the harder to reach raw materials. The initially assigned EF values for products such as these, that may be capped in order to keep inflation low, can also be increased over time as more and more alternative products with higher sustainability are brought to market and as more consumers switch to those alternatives. As an example, electric cars will start out with low EF values and these should remain low over time, driving consumers to use these products as opposed to gasoline powered cars. In contrast, those who choose to drive gasoline and diesel cars will become smaller in number, allowing the EF value for these products to rise, without significantly impacting inflation, because the overall consumption of these "bad" products will decrease with time. Therefore, the loss of taxation revenue due to the lower volume of sales from the consumption of "bad" products may be offset with higher EF values for future transactions.

Conceivably, EF values can be adjusted to as high as 6.27, meaning the cost of bad products in the future could be over $600 \%$ higher than they are today. This is based on an EF value of 1.3 for all seven of the externality categories with 1.3 multiplied times the production cost seven times consecutively. Cost increases of even half this amount should be enough to make the production of bad products impractical, and hence eventually these kinds of products will be forced off the market, even though large amounts of the raw materials remain in the earth. Again, though, the overall inflation experienced in a given economy must and will be controlled so as to not allow individual product's costs to impact inflation substantially, with EF values adjusted accordingly over time. Even 
so, revenue from a taxation system such as proposed here will not be dramatically or suddenly affected by the elimination of just certain bad products, there are expected to always be plenty of non-sustainable goods and services with which to assign high EF values to, in order to more than offset those products with low EF values. Further, if this taxation system is used to supplant other taxation systems such as income taxes, then EF values and EF caps can be adjusted as needed to meet revenue requirements accordingly.

In fact, the potential for a broad range of potential EF values, combined with the needed flexibility of a system such as this does make it possible to target particularly bad goods with higher EF values as needed in order to discourage the production of those goods. Those goods that can be directly attributable to GCC can be given higher EF values initially in order to quickly direct consumerism elsewhere. As examples, lumber obtained from deforested tropical forests and beef grown in those same locations can be targeted with very high EF values in order to force those businesses to move out of tropical forests entirely. In the same way, very high EF values can be assigned to oil extracted from deep-sea wells or from other delicate natural resource locations.

On the opposite end of the spectrum, products that are extraordinarily valuable to the environment and in turn, society, can be rewarded with a total EF adjustment down to just $20 \%$ of the production cost. This is the highest potential benefit possible with an EF system as described here, with an EF value of 0.8 for all seven categories with 0.8 multiplied times the production cost seven times consecutively. These funds are then paid back to the retailer after the final point of sale. An example of this may be locally grown plants with high carbon uptake and a long life expectancy. Thus, a local tree nursery may sell a tree sapling for $\$ 1.00$ and can potentially be rewarded with $\$ 0.80$ for every tree they sell at the retail level. These trees, in fact, could be grown near tropical rainforests and transplanted to these same forests in an effort at reforestation with native species. This kind of a scenario, although possible, however, is only likely if the overall economy has an abundance of revenue from the production and sale of other high externality products. Initially and for the foreseeable future, very good products are expected to have a modestly low EF, allowing a good return to the retailer, but not at the potential of an $80 \%$ benefit for some time to come.

And what about the need for oversight by professional economists, working on behalf of the governments involved and the United Nations? This need, in fact, is crucial both before implementation of a system such as this EF taxation and subsidy system, and after it is implemented as well. Macroeconomic and microeconomic monitoring are needed on an ongoing basis, with perhaps particular attention paid to inflation measurements. As inflation rises, adjustments to the EF values will need to be made to counter this trend, relying on the expertise of the economists hired to perform this analysis. Without the support of professional economists, moreover, a system like this should not be implemented. Even so, the use of AI, with sufficient feedback and optimization with the correct algorithms should make the work of economists manageable as the price of goods and services can be automatically corrected and adjusted over time with the purpose of protecting the economy and those with lower incomes.

So who is going to be the one to come up with all of these EF values for all of society's goods and services? The answer is that the vast majority of this work needs to be done by businesses for their own goods and services, and this work needs to be done with input from consumers. Naturally, this will require oversight from an independent entity, such as an independent government agency. In the US, as an example, the Internal Revenue Service (IRS), or a new bureau if the IRS is not adequate for setting guidelines and rules, may provide EF establishment guidelines, while also providing monitoring and oversight of the firms assigned EFs for goods and services, as well as the auditing of EF payments to the government. This responsibility must also include the development of programming and the algorithms to estimate EF values given the inputs needed and the flexibility needed to make assumptions about impacts in the seven or more categories. Again, the creation of EF values can be accomplished by all of an industry for its individual goods and services, and they will be doing so based on wellestablished and sufficiently complete guidelines provided by the federal government with input from their industry.

What is the incentive for industry to perform these complex calculations and given the enormity of the task, can government taxation agencies such as the IRS really be expected to implement and monitor a system such as this? As mentioned earlier, a system such as this must rely on modern computational means with the needed programming and algorithms to perform the lion's share of the work. The role of any government taxation agency must then be focused on the development, oversight, monitoring and enforcement requirements. Industry, on the other hand, will be responsible for the implementation of the EF pricing, given the expected caps on the high and low EF assigned values based on the programs provided by government, and compliance with the regulations set in place by the government. The incentive for industry is both for the need to comply with regulations and the more positive need to be competitive with others in their industry. And as has already been seen with many companies today, the benefits of a more sustainable business often do outweigh the costs required for the implementation of sustainable business activities (Savitz and Weber, 2014).

This large task of assigning EFs to all goods and services can also be aided by information gained from ecolabeling, green labeling, manufacturers statements on their own products, corporations annual reports, other 
internal documents, appliance energy star ratings and a host of other consumer and industry information that is readily obtained. In those cases where the EFs cannot be obtained from the businesses, these can be assigned by a government entity, and in the US, again - as an example; this can be accomplished by an agency such as the IRS. Again though, the majority of this work is going to be in the programing of computers who will then carry on with the day to day task of assigning EF values, changing them over time, all based on a multiple of inputs and with safeguards in place to control inflationary pressures as well as the needs of lower income consumers.

Some will argue as well that a taxation-subsidy system based on income derived from negative externalities is doomed to run out of revenue generating capacity as both consumer and producer behaviors change over time. The concern here is that an economy that depends on a "bad" source of revenue is doomed to fail once consumers switch to "good" products. And this would be a grave concern if the system did not have built-in flexibility for adjustment and phase-in of differing EF values over time, adjusting EF values upwards as the economy permits and as more and more companies become more sustainable. In addition, this EF taxation and subsidy system is intended to provide grants and subsidies, further aiding future economies. Further, if our tendency to produce positive externalities was anything like our propensity to produce negative externalities, we would have real cause for concern as time moves forward. The harsh reality, though, is that we as a species, will always produce negative externalities and as we improve in these areas, the accounting system will need to be adjusted from one of grossly underestimating the cost of externalities to one that moderately accounts for the cost of externalities. Again - the need is to influence consumer behavior, however, this is done with the knowledge that most of our best producers of goods and services will never quite achieve negative externality - free extraction, production, packaging, transportation, and sale of goods and services and that do not themselves create negative externalities after the point of sale.

Since, however, the EF system provides an incentive for consumers and firms to move in a more ecologically sustainable direction, there is still the possibility that EF taxes could become "self-repealing." That is, as fewer and fewer people and firms choose items that have higher prices due to EF taxes, it is possible that subsidy or incentive amounts to firms and individuals can outweigh EF tax revenues. In this case, as stated earlier, it may be necessary to tax the increases in the values of the firm and household property that have benefitted from cleaner and healthier environments in order to pay for continued sustainability practices. This tax would only be on increases in land property values occurring after the implementation of an EF system, and thus would be a form of tax-incremental financing.

\section{CONCLUSION}

The accounting for externalities and the use of externality factors is provided here as a supplement to our existing system of capitalism intended as a stopgap measure to exploit those same forces that make capitalism so resilient. This system is not intended to supplant the need for strict environmental laws and the necessity for legal actions against those who violate those laws. Rather, the goal here is to use this same desire for wealth accumulation that makes capitalism so strong, infectious and powerful, and to use these desires for the advantages of all of humanity, and perhaps more importantly for our natural systems (McKibben, 2011). This EF accounting system is meant to stem the tide of continued fossil fuel use and continued natural resource degradation. It is not meant to be a permanent remedy for our economic system or to address the deprivation of our human nature, which is at least as much to blame for our destructive behaviors as is our economic system (Kovel, 2007; Lilley et al., 2012). This is a 'lets try this now because nothing else is working approach' - under the premise that our societies are out of time - and then continuing on with a willingness to adjust the system as needed, refining as necessary and correcting the changes as needed in order to avoid disruptions to the economy.

Emphasis is placed on the need to estimate externality taxes and subsidies as opposed to getting bogged down with an attempt to accurately represent externality costs in the form of an externality tax or green tax. Existing imprecise taxes known as "sin taxes" and even income taxes can be replaced with an EF accounting system that can be phased in over time. These taxes and other more pertinent and yet imprecise taxes such as carbon and ecotaxes can be completely replaced with a more broad-brushed EF taxation system. As an example, the application of an externality tax to any good or service can use a similar taxation methodology applied to these goods, thereby, eliminating the need for a high degree of accuracy, by not attempting to equate the tax with the true and actual cost of the externality (Hawken, 2010). Importantly, computational means with well-designed algorithms will put limits on EF values in order to accommodate inflationary pressures and to allow producers to change their processes for the betterment of society and the environment. In addition, the use of AI with critical feedback information will help to ensure that inflationary pressures are under control and that lower income consumers are not unfairly affected by the cost of higher externality goods and services.

The goals are obvious - use capitalistic forces and governmental incentives and disincentives to encourage good consumption and discourage bad consumption. The focus here is entirely on consumer and producer behaviors, 
relying on changes in those behaviors to modify consumer purchases, and alter the production, extraction and transportation practices of goods and services. Retailers, producers, distributors and essentially all business enterprises will have incentives to sell goods and services with lower EF values. Consumers' buying patterns will effectively pressure all industries to reduce their carbon footprints, improve the efficiencies of their operations, dissuade them from taking advantage of their workforce and stop them from participating in harmful practices to the environment (Coghlan, 2009). The implementation of an EF accounting system such as discussed in this paper allows for an ongoing progressive and responsive influence on consumer behavior for the betterment of society, the environment and addresses microeconomic as well as macroeconomic needs. Thus, in turn, the anthropogenic production of different kinds of negative externalities will decrease with time, due to the powerful market influence of consumption behavior. Our consumption patterns will change for the better and notably, certain goods and services' higher prices will encourage consumers to purchase less overall. The consumer will be motivated by lower prices and lower EF values for goods and services. The same will motivate the producers and retailers, and in the not too distant future, our system of capitalism will end its war against nature.

\section{REFERENCES}

Andersen, M. S. (2007). An introductory note on the environmental economics of the circular economy. Sustainability Science, 2(1), 133-140. https:// doi.org/10.1007/s11625-006-0013-6

Assessment, M. E. (2005a). Ecosystems and human well-being: Synthesis. Washington, DC: Island Press.

Assessment, M. E. (2005b). Living beyond our means: Natural assets and human well being (Statement of the MA Board). Available at: http:/ /www.millenniumassessment.org (Accessed 14 March 2014)

Assessment, M. E. (2005c). Millennium ecosystem assessment: Statement from the MA Board. Available at: http://www.millenniumassessment.org./en/BoardStatement.html (Accessed 14 March 2014)

Beeks, J. C. (2016). Which of the current diverse ideas on alternative economics are the best for adequately and comprehensively addressing the great transition to climate, energy, and biodiversity sustainability? (Doctoral dissertation, California Institute of Integral Studies San Francisco, CA). Available at: https://search.proquest.com/openview/aedc7d6b22498c95c2199f79c446f56c/1?pqorigsite $=$ gscholar\&cbl $=18750 \&$ diss $=y$

Behravesh, C. B., Williams, I. T. and Tauxe, R. V. (2012). Emerging foodborne pathogens and problems: Expanding prevention efforts before slanghter or harvest. Washington, DC: National Academies Press.

Benyus, J. M. (1997). Biomimicry. New York, NY: William Morrow.

Bernstein, R. J. (2006). The abuse of evil: The corruption of politics and religion since 9/11. Malden, MA: Polity Press.

Bloomberg Financial (2017). Electric vebicle outlook 2017. Available at: https://about.bnef.com/electric-vehicleoutlook/

Carbon Tax Center. (2016). Carbon tax center: States. Available at: https:/ /www.carbontax.org/states/

Coase, R. H. (2013). The problem of social cost. Journal of Law \& Economics, 56, 4. https:/ / doi.org/10.1086/674872 Available at: http://www.journals.uchicago.edu/doi/abs/10.1086/674872?journalCode=jle

Coghlan, A. (2009). Consumerism is 'eating the future'. New Scientist, August, 2009. Available at: https://www.newscientist.com/article/dn17569-consumerism-is-eating-the-future/

Costanza, R., de Groot, R., Sutton, P., van der Ploeg, S., Anderson, S. J., Kubiszewski, I., Farber, S. and Turner, R. K. (2014). Changes in the global value of ecosystem services. Global Environmental Change, 26, 152-158. https://doi.org/10.1016/j.gloenvcha.2014.04.002

Costanza, R., de Groot, R., Braat, L., Kubiszewski, I., Fioramonti, L., Sutton, P., Farber, S. and Grasso, M. (2017). Twenty years of ecosystem services: How far have we come and how far do we still need to go? Ecosystem Services, 28, 1-16. https://doi.org/10.1016/j.ecoser.2017.09.008

Daly, H. E. (2009, June 1). From a failed growth economy to a steady state economy. The encyclopedia of Earth. Available at: http://www.eoearth.org/

Derber, C. (2010). Greed to green: Solving climate change and remaking the economy. Boulder, CO: Paradigm Publishers.

Eisenstein, C. (2007). The ascent of humanity. Harrisburg, PA: Panenthea Press.

Eisenstein, C. (2011). Sacred economics: Money, gift, and society in the age of transition. Berkeley, CA: North Atlantic Books.

Externality. (2015). Oxford dictionaries. Available at: http://www.oxforddictionaries.com/us/definition/american_english/externality

Flannery, T. F. (2006). The weather makers: How man is changing the climate and what it means for life on earth. New York, NY: Grove Press.

George, H. (1881). Progress and Poverty: An Inquiry into the Cause of Industrial Depressions and of Increase of Want with Increase of Wealtb; The Remedy. Kegan Paul (reissued by Cambridge University Press, 2009; ISBN 978-1-10800361-2)

Gramlich, E. M. (1990). A guide to benefit-cost analysis (2nd ed.). Englewood Cliffs, NJ: Prentice Hall. 
Hawken, P. (2010). The ecology of commerce: A declaration of sustainability (3rd ed.). New York, NY: Harper Collins Business.

Hawken, P. and Steyer, T. (2017). Drawdown: The most comprehensive plan ever proposed to reverse global warming. New York: Penguin Books.

Houghton, J. T. (1996). Climate change 1995: The science of climate change: Contribution of working group I to the second assessment report of the intergovernmental panel on climate change. Cambridge, UK: Cambridge University Press.

Hsu, S. L. (2008). Carbon tax heuristics and politics: The case of the gasoline tax. Tallahassee, FL: Florida State University. https://doi.org/10.2139/ssrn.1121039

Hunt, E. (1980). A radical critique of welfare economics. In E. J. Nell (Ed) Growth, Profits, and Property (pp. 239249). New York, NY: Cambridge University Press. https://doi.org/10.1017/CBO9780511571787.016

Intergovernmental Panel on Climate Change (IPCC). (2007). Projected climate change and its impacts. Available at: http://www.ipcc.ch/publications_and_data/ar4/syr/en/spms3.html

Kapp, L. L. (1978). The social costs of private enterprise (3rd ed.). Nottingham, UK: Russell Press.

Klein, N. (2014). This changes everything. New York, NY: Simon \& Schuster.

Klugler, J. (2014). The sixth great extinction is underway - and we're to blame. Time science. Available at: http://time.com/3035872/sixth-great-extinction/

Kovel, J. (2007). The enemy of nature: The end of capitalism or the end of the world (2nd ed.). New York, NY: Zed Books.

Kraft, M. E. and Furlong, S. R. (2015). Assessing policy alternatives, Ch. 6 in Public policy: Politics, analysis, and alternatives (5th ed.). Thousand Oaks, CA: Sage/CQ Press.

Krugman, P. (2010). Building a green economy. The New York Times Magazine, p. 1-16. Available at: http://www.ohipl.org/sites/default/files/KrugmanNYT.pdf

Lee, Jr., R. D., Johnson, R. W. and Joyce, P. G. (2013). Public budgeting systems (9th ed.). Burlington, MA: Jones and Bartlett Learning.

Lilley, S., McNally, D., Yuen, E., Davis, J. and Henwood, D. (2012). Catastrophism: The apocalyptic politics of collapse and rebirth. Oakland, CA: Pm Press.

Hauser, R. and Blume, R. (2011). A Natural Step case study: Nike. Available at: https://www.northlakecollege.edu/au/sustainability/facsustainresources/bizecon/bizecoresources/documen ts/nike.pdf

Mankiw, N. G. (2015). Externalities, chapter 10 in Principles of economics, (7th ed.). Stamford, CT: Cengage Learning.

Martinez Alier, J. (1988). Ecological economics and eco - socialism. Capitalism Nature Socialism, 1(2), 109-122. https://doi.org/10.1080/10455758809358372

Martinez Alier, J. (1995). The environment as a luxury good or “too poor to be green"? Ecological Economics, 13(1), 1-10. https://doi.org/10.1016/0921-8009(94)00062-Z

Marwala, T. and Hurwitz, E. (2017). Artificial Intelligence and Economic Theories. arXiv preprint arXiv:1703.06597. Available at: https://arxiv.org/pdf/1703.06597.pdf

McKibben, B. (2006). The end of nature. New York, NY: Random House, Inc.

McKibben, B. (2011). eaarth: Making a life on a tough new planet. New York, NY: St. Martin's Press.

Montuori, A. (2005). Gregory Bateson and the promise of transdisciplinarity. Cybernetics and Human Knowing, 12(12), $147-158$.

Montuori, A. (2008). Foreword: Transdisciplinarity. In B. Nicolescu (Ed.), Transdisciplinarity: Theory and practice (pp. ix-xvii). Cresskill, NJ: Hampton Press. https://doi.org/10.1002/qua.21708

Pearce, D. (2002). An intellectual history of environmental economics. Annual Review of Energy and the Environment, 27(1), 57-81. https://doi.org/10.1146/annurev.energy.27.122001.083429

Pearce, D., Markandya, A. and Barbier, E. (1989). Blueprint for a green economy. London, UK: Earthscan Publishing.

Pepper, D. (2002). Eco-socialism: From deep ecology to social justice. New York, NY: Routledge.

Pigou, A. C. (2013). The economics of welfare. New York, NY: Palgrave Macmillan.

Protocol, K. (1997). United Nations framework convention on climate change. Kyoto Protocol, Kyoto, Japan.

Rae, K. and Sands, J. (2013). Creating sustainable benefits for stakeholders of organizations using the strategy mapping framework. E-Journal of Social and Behavioral Research in Business, 2(4), 14-33. Available at: https:/ / eprints.usq.edu.au/26735/1/Rae_Sands_eJSBR_2013_PV.pdf

Savitz, A. W. and Weber, K. (2014). The triple bottom line: How today's companies are achieving economic, social and environmental success - and how you can too. Indianapolis, IN: Jossey-Bass.

Senge, P. (2006). The fifth discipline: The art and practice of the learning organization. New York, NY: Doubleday Publishing.

Simon, H. (1957). A behavioral model of rational choice, in Models of man, social and rational: Mathematical essays on rational buman behavior in a social setting. New York, NY: Wiley

Solomon, S. (2007). Climate change 2007-the physical science basis: Working group I contribution to the fourth assessment report of the IPCC. Cambridge, MA: Cambridge University Press. 
Spash, C. L. (2010). The brave new world of carbon trading. New Political Economy, 15(2), 169-195. https://doi.org/10.1080/13563460903556049\#.UerTmZgiPIU Available at: http:/ /www.clivespash.org/2010_Spash_Brave_New_World_NPE.pdf

Trainer, T. (2011). The radical implications of zero growth economy. Real-World Economics Review, 57(1), 71-82.

Turner, R. K., Pearce, D. and Bateman, I. (1994). Environmental economics: An elementary introduction. Hemel Hempstead, UK: Harvester Wheatsheaf.

Victor, P. (2008). Managing without growth: Slower by design, not disaster. Cheltenham, United Kingdom: Edward Elger Publishing Limited. https:/ / doi.org/10.4337/9781848442993

Vineis, P. and Husgafvel-Pursiainen, K. (2005). Air pollution and cancer: biomarker studies in human populations. Carcinogenesis, 26(11), 1846-1855. https://doi.org/10.1093/carcin/bgi216

Wells, J. (2013). Complexity and sustainability. New York, NY: Routledge.

Zerio, J. and Conejero, M. A. (2009). Global sustainability: The case for collaboration. Case study TB0019. Thunderbird school of global management. 